
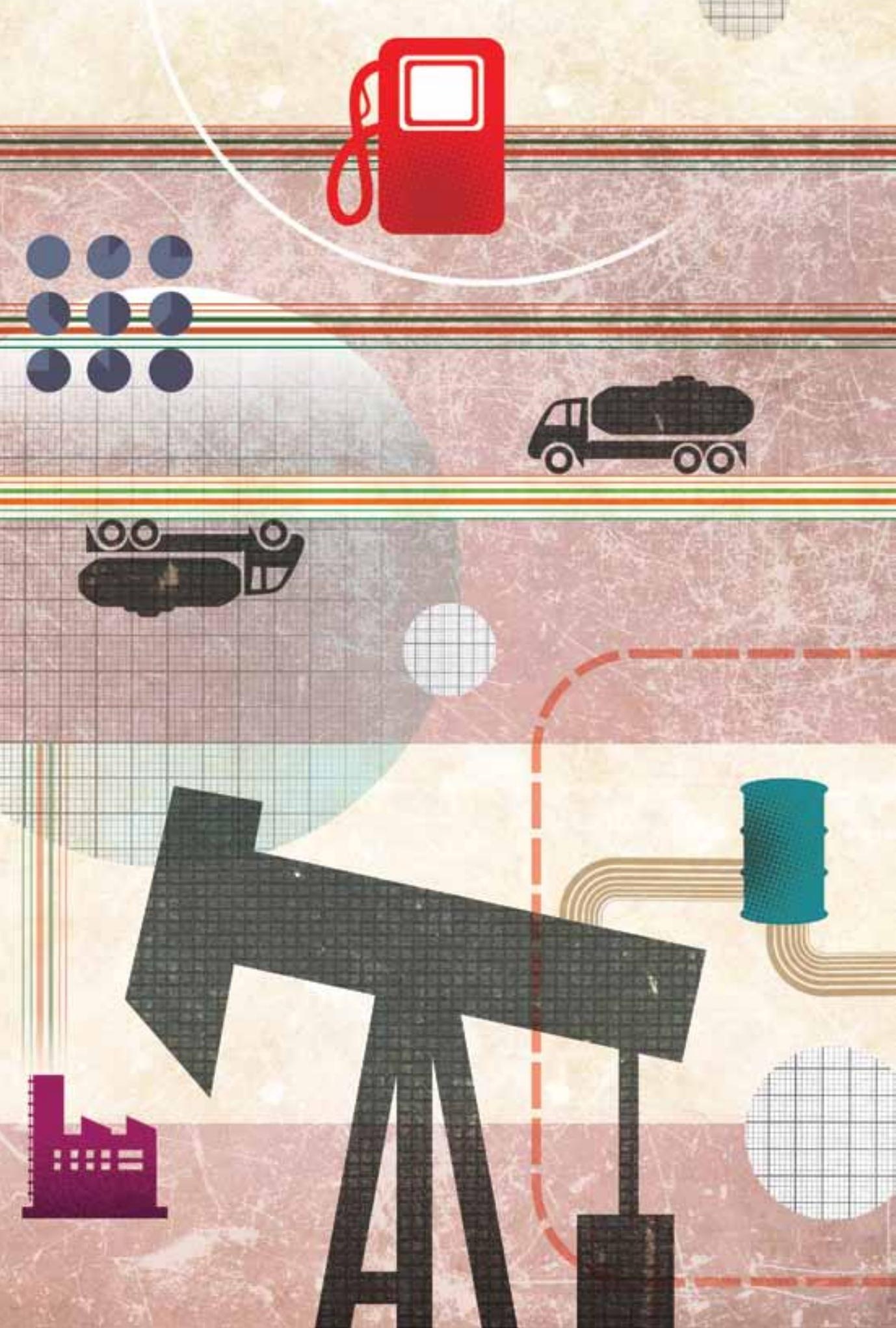


\title{
Políticas Públicas, atores e regras: uma perspectiva neoinstitucionalista da dinâmica do Programa Nacional de Produção e Uso de Biodiesel
}

\author{
Public Policies, actors and rules: an \\ neo-institutionclist perspective of the \\ dynamics of the "National Program of \\ Production and Use of Biodiesel"
}

Georges Flexor

Resumo

O artigo esboça um quadro de análise do processo de formulação de políticas que privilegia a dinâmica da relação entre instituições e comportamentos dos atores. Para tanto, recorre a aportes teóricos desenvolvidos por autores neoinstitucionalistas. A partir dessa estrutura analítica, proporciona-se uma análise do processo de formulação do Programa Nacional de Produção e Uso de Biodiesel. A análise dessa política tem por objetivo de mostrar como uma abordagem neoinstitucionalista auxilia a apreensão dos elementos e das relações entre os elementos pertinentes à compreensão da ação pública, de seus resultados e de sua dinâmica.

Palavras Chaves: Políticas Públicas, Institucionalismo, Biocombustíveis

\begin{abstract}
The article outlines a framework for analyzing policy process. Specifically, the framework emphasizes the dynamic relationship between institutions and actor's behavior. It is based on neo-institutionalists approachs of policy process. Based on this analytical framework, the article provides an analysis of the formulation of the National Biodiesel Production and Use Program. The analysis of this policy aims to show how a neo-institutionalist approach help the understanding of the elements and the relationships between the elements relevant to analysis of public action, its results and its dynamics
\end{abstract}

Keywords: Public Policy, Institutionalism, biofuel 


\section{Introdução}

Como analisar o modus operandi das atividades do Estado e suas conseqüências sobre a vida das pessoas? Em que medida as motivações dos atores e as regras que estruturam suas interações influenciam o processo de formulação de políticas? Como resolver problemas comportamentais e institucionais que afetam a qualidade dos programas e projetos públicos? É para responder a essas questões que a análise das políticas públicas (policy analysis) se desenvolveu como disciplina acadêmica nos anos 1960, estimulada intelectual e financeiramente pelo crescimento do escopo de atuação das atividades governamentais decorrente do avanço do Estado de Bem Estar nos países industrializados ou dos projetos desenvolvimentistas em diversos países em desenvolvimento.

Desta época, a disciplina guarda uma constante orientação multidisciplinar e uma atenção especial às possibilidades de análise da ação pública capazes de construir conhecimentos e desenvolver instrumentos para "mudar o mundo" características originais acompanharam o desenvolvimento da análise das políticas públicas como disciplina acadêmica e explicam tanto seu crescimento como sua importante diversidade teórica e metodológica. Graham Allison (1971) na sua clássica exposição dos processos decisórios durante a crise dos mísseis em Cuba de outubro de 1962 já destacava a existência de diversos modelos analíticos explicando os processos decisórios públicos ${ }^{2}$. O trabalho mostrava de forma pioneira que a compreensão de uma política e de seus impactos sociais e econômicos depende fundamentalmente das variáveis escolhidas para organizar a pesquisa, estruturar a narrativa e estabelecer um possível diagnóstico. Como lembram, entre outros, Nelson (1996) ou Sabatier (2007), essa diversidade teórica continua sendo, nesse início do século XXI, uma característica da análise das políticas públicas. O mesmo pode ser dito a respeito do desejo de produzir conhecimentos aplicáveis, embora de forma não tão explícita.

A diversidade e a heterogeneidade científica são provavelmente inerentes a complexidade do processo de formulação de política. ${ }^{3}$ No entanto, para manter sua legitimidade política e acadêmica, a análise das políticas públicas deve também privilegiar alguns eixos teóricos. Trata-se de uma evolução necessária já que o desenvolvimento da disciplina precisa explorar ideias e aprofundar conhecimentos e informações produzidos pela pesquisa.

Este artigo procura apresentar um quadro de análise do processo de formulação de políticas que privilegia a dinâmica da relação entre instituições e comportamentos dos atores. Mais especificamente, explora as contribuições teóricas de vários autores interessados em analisar a formulação de políticas a partir da compreensão das intenções dos atores e das regras (formais ou informais) que estruturam suas interações. Nesse sentido, as idéias articuladas nesse artigo defendem a exploração dos aportes teóricos desenvolvidos por autores neoinstitucionalistas como Ostrom (1990, 2005), Scharpf (1997) e outros, destacando a fecundidade epistemológica e metodológica de 
suas estruturas analíticas. Para ilustrar as possibilidades proporcionadas pelo quadro de análise apresentado na primeira parte do artigo, proporciona-se uma análise do processo de formulação do Programa Nacional de Produção e Uso de Biodiesel. A análise dessa política tem por objetivo de mostrar como uma abordagem neoinstitucionalista auxilia a apreensão dos elementos e das relações entre os elementos pertinentes à compreensão da ação pública, de seus resultados e de sua dinâmica.

\section{Elementos de um quadro de análise neoinstitucionalista das políticas}

O quadro de análise esboçado nessa seção procura identificar as variáveis de uma abordagem neoinstitucionalista das políticas. Combina contribuições teóricas diferentes, porém convergentes no que diz respeito aos pressupostos básicos necessários a compreensão do processo de formulação. Em primeiro lugar, almeja proporcionar uma explicação intencional da ação pública. As ações dos agentes refletem suas preferências, crenças, viés cognitivos e recursos. Além disso, como supõe que na maioria dos estudos a análise da política deva focar as estratégias das coalizões ou redes de atores e seus padrões de interação admite que a explicação intencional possa ser aplicada a atores coletivos. O segundo pressuposto básico do quadro de análise neoinstitucionalista diz respeito à centralidade das estruturas institucionais nesse processo. Enquanto sistemas de incentivos e restrições, as regras formais ou informais prescrevem, proscrevem ou permitem certos comportamentos (Ostrom, 2003). Assim, de uma forma ou outra, a estrutura institucional molda uma situação de interdependência entre atores e entre grupos de atores que tem conseqüência sobre dinâmica da política. Em particular as regras influenciam a distribuição dos benefícios e custos da ação pública já que como afirma Schmid (2005) o desempenho de uma política é antes de tudo o problema de saber quem recebe o quê.

A apresentação do quadro de análise inicia com algumas idéias sobre os atores e seus comportamentos. Segue com uma apresentação das funções e dos atributos básicos das regras. Considera então os elementos institucionais constitutivos das situações de interdependências próprias aos processos de formulação das políticas. Por fim, tece considerações sobre os mecanismos de mudanças da política como a distribuição dos benefícios e custos, os processos de aprendizagem e os feedback sobre os condicionantes externos e os comportamentos dos atores.

\section{Os atores}

Analisar o comportamento dos atores e sua influencia sobre o processo de formulação das políticas públicas pressupõe que se adota uma explicação intencional das ações humanas, individuais e coletivas. A abordagem da escolha racional propõe um modelo claro e bem definido das relações entre pressupostos comportamentais 
dos atores e os resultados coletivos de suas decisões. Defende a idéia de que os agentes fazem o máximo que podem, ou seja, maximizam uma função objetiva dado um conjunto de restrições. ${ }^{4}$ Como destaca Ostrom (2000), essa caracterização dos comportamentos humanos pode ser bem sucedida para explicar as decisões tomadas por atores bem informados e posicionados num contexto político, econômico ou social competitivo, onde os mecanismos de seleção eliminam os comportamentos que não seguem o principio da maximização. Nesses contextos sociais, os atores se comportam como se fossem motivados pelo principio de maximização. Contudo, a teoria da ação racional é ineficaz para entender ou prever os comportamentos quando o contexto de interdependência se distancia do ideal dos mercados e eleições competitivos. Esta observação leva Ostrom a advogar a substituição do modelo da escolha racional por uma teoria da racionalidade limitada (Simon, 1955) que concebe as condutas humanas de forma complexa e dinâmica, sujeitas a erros grosseiros e que buscam se adaptar e aprender nas situações onde se encontram ${ }^{5}$.

Na perspectiva intencional defendida por Ostrom (1998, 2005), Schmid (2005), Elster (2010) e outros, a explicação dos comportamentos deve também incluir os valores e os vieses cognitivos e emocionais que influenciam os juízos e decisões dos atores. A importância do impacto desses fatores nas escolhas e comportamentos dos atores já tinha sido destacada pela teoria da dissonância cognitiva elaborada por Festinger (1957) ${ }^{6}$. Mas, recentemente, a insatisfação com o modelo de racionalidade maximizadora tem encontrado um público mais amplo e é crescente a literatura de psicólogos experimentais, economistas comportamentais, filósofos e outros que tratam do papel das emoções, valores e viés cognitivos nas decisões humanas. Entre os trabalhos mais influentes cabe citar os dos psicólogos Kahneman e Tversky (1984) ou Tversky e Shafir (2004). Mostram, em particular, que os atores cometem erros e realizam juízos tendenciosos porque escolhem as informações mais disponíveis, em vez das mais proveitosas. Evidenciaram também que as decisões dos indivíduos ancoramse geralmente num conjunto restrito de informações e não todas as informações disponíveis. O otimismo ou a confiança excessiva representam também vieses recorrentes assim como o fato de que as pessoas realizam escolhas se baseando mais no que outros agentes fazem ou dizem do que em uma cuidadosa análise dos custos e benefícios esperados. Thaler e Sustein (2008) ou Akerlof e Shiller (2009) lembram que esta propensão acaba produzindo um "efeito manado" com conseqüências importantes sobre o curso da política. E como nota Schmid (2005), os vieses cognitivos têm implicações sobre o comportamento dos juízos, júris e cidadãos e, também, dos políticos, membros de equipes de governos, grupos de interesses ou sindicatos, o que acaba impactando o processo de formulação e os resultados da política.

Os atores, além disso, podem mostrar comportamentos irracionais (do ponto de visto da racionalidade maximizadora) devido a comportamentos temporalmente inconsistentes. Por exemplo, podem preferir ganhos efêmeros, mas imediatos, a recompensas duradoras, porém desfrutadas ulteriormente. Elster (2010) analisa 
essa falha da racionalidade como uma conseqüência do desconto hiperbólico ${ }^{7}$ que perturba os mecanismos de decisões dos atores. O filósofo norueguês sublinha que de maneira geral existe a necessidade de incorporar as emoções, as paixões e as outras formas de irracionalidade que formam a "alquimia da mente" às explicações intencionais dos comportamentos humanos. Para o autor, o afastamento do ideal científico representado pela concepção estreita (maximizadora) da racionalidade é o "preço a pagar" para melhorar a compreensão das ações humanas.

Antes de abordar a questão das regras, cabe notar que além de levar em conta os vieses cognitivos e emocionais que afetam geralmente as decisões individuais, a análise neo-institucionalista da formulação de política deve também adotar uma perspectiva para lidar com os atores coletivos - como as coalizões, as redes sócioeconômicas, associações, ministérios, empresas. No quadro de análise considera-se que é epistemologicamente possível transpor aos atores coletivos e organizacionais o tipo de pressupostos analíticos - racionalidade limitada, vieses cognitivos, etc. - aceita para a compreensão das ações individuais. È necessário, no entanto, avaliar com cuidado as características dos atores coletivos no jogo da política. Uma coalizão agindo coletivamente para obter ganhos de um programa governamental apresenta estratégias temporalmente menos consistentes e, portanto, críveis do que uma comunidade caracterizada por crenças estáveis e valores enraizados nas expectativas dos seus membros. Atores como ministérios ou empresas têm fronteiras organizacionais mais bem definidas do que coalizões, redes ou movimentos sociais. Desenvolvem geralmente uma identidade, recursos e objetivos que lhe são próprios, garantindo certa autonomia em relação aos demais atores da política. Dada essa autônoma relativa, atores organizacionais com uma cultura forte tendem a elaborar estratégias que limitam a adaptabilidade da política ao longo do tempo. Isto pode ser um aspecto positivo na medida em que garante a credibilidade do comprometimento da ação pública. Mas isto pode também elevar os custos de ajustes e transição quando surge a necessidade de se alterar os cursos de um programa. Em definitiva, se a abordagem neoinstitucionalista aceita transpor aos atores coletivos e organizacionais pressupostos analíticos adotados para os atores individuais, ela precisa também incorporar as características específicas desses atores na análise dos processos de formulação da política.

\section{As regras}

As regras são, ao lado dos atores, as variáveis privilegiadas pela análise neoinstitucionalista para entender os modos de interação e seus impactos sobre o rumo das ações públicas. Para Ostrom (2005), os padrões de interação são fundamentados em regras que os atores usam para dar ordem à suas relações. No quadro de sua análise institucional, as regras devem ser entendidas como meios de prescrever, proscrever ou permitir certos comportamentos. As regras desempenham assim uma série de função: 
1) elas criam posições; 2 ) instituem como os participantes adquirem ou deixam suas posições; 3) estabelecem o leque de ações requeridas, permitidas ou proibidas e; 4) elencam os resultados requeridos, permitidos ou proibidos. Essas funções representam a chave para entender os incentivos e restrições que estruturam os padrões de interação que caracterizam a situação de interdependência de uma política.

No intuito de elaborar um arcabouço teórico capaz de dar conta da diversidade das estruturas institucionais Crawford e Ostrom (1995) lançam mão de uma sintaxe geral das regras, denominada ADICO (Attributes, Deontic, Aim, Conditions, Or Else). Segundo as autoras, existem cinco componentes básicos da sintaxe institucional. O primeiro elemento relaciona-se com o conjunto de atributos (Attributes) que estabelecem os grupos de atores afetados por uma estrutura institucional (conjunto de regras). Políticas industriais que obrigam certo índice de conteúdo nacional na produção de bens e serviços afetam diferentemente as empresas capazes de fornecê-los. O segundo componente (Deontic) distingue os aspectos prescritivos e consiste em operador lógico do tipo pode, deve ou não deve. Uma política ambiental visando diminuir a poluição atmosférica nas grandes cidades pode estabelecer, por exemplo, que as emissões de gases dos automóveis não devem ultrapassar certos níveis de poluentes. O objetivo ou a intenção (Aim) institui a relação entre uma ação ou os resultados e os aspectos prescritivos das regras. No caso da política de controle de emissões de poluentes, as regras relacionam um objetivo (a melhoria do ar) com mudanças nas normas de qualidade da gasolina e da tecnologia automobilística. No entanto, a operacionalização dos objetivos e intenções depende das condições (Conditions) em que se aplicam. No exemplo da política de conteúdo nacional, alguns objetivos como o desenvolvimento de insumos considerados estratégicos pelo governo podem ser impossíveis por inúmeras razões. Governos alheios podem ameaçar retaliar a política considerada protecionista, levando ao abandono da mesma pelas autoridades vigentes. A indústria nacional de insumos pode também se mostrar incapaz de desenvolver os produtos desejados e a política não tem condição de ocasionar resultados concretos, etc. Por fim, a sintaxe institucional compreende um componente associado ao não cumprimento das regras (elemento OrElse). Assim, os automóveis que não se adequam aos objetivos da política ambiental correm o risco de serem multados e as empresas que não incorporam conteúdo nacional podem ser impossibilitadas de comercializar seus produtos ou concorrer a licitações públicas. Esses componentes básicos das regras têm por conseqüência que mudanças de regras afetam a posição dos participantes - incluem ou excluem alguns atores - alteram o valor dos seus recursos, concedem ou enfraquecem direitos, alargam ou diminuem o escopo dos resultados possíveis e,de maneira geral, modificam os incentivos.

\section{Atores, situações interdependências e mudança na política}

Após destacar as motivações e capacidades dos atores e os papeis desempenhados pelas regras, o quadro de análise neoinstitucionalista das políticas deve se perguntar 
como se institucionaliza relações de interdependência entre diversos atores e como esse processo muda "estado do mundo". A estrutura analítica sintetizada na figura 1 procura tratar dessa questão. Ela pode ser compreendida da seguinte maneira: a formulação de uma política pública representa uma situação de interdependência determinada não somente por restrições constitucionais, tecnológicas e biofísicas, mas pelas preferências e recursos dos atores engajados em ações coletivas e interagindo ao longo do tempo num quadro institucional que se modifica. Portanto, nessa estrutura analítica, os atores, os grupos e constelações de atores e os padrões de interação que caracterizam a situação de interdependência são as principais variáveis que sustentama análise da política e de seus resultados. Além disso, supõe-se que os efeitos distributivos e alocativos da política pública devem ser analisados como conseqüências - muitas vezes inesperadas - da ação ou inação de atores e redes de atores e das regras formais e informais que estruturam suas interações. Por fim, o modelo interpretativo sustenta que a inadequação dos resultados aos objetivos esperados, os conflitos distributivos, os processos de aprendizagem e os mecanismos de auto-reforço suscitam efeitos de feedback - a seta em curva na figura - sobre as preferências e crenças dos atores, as regras que enquadram suas interações e, em certos casos, as variáveis exógenas como a tecnologia e o aparato constitucional. Pretende-se como isso incorporar a questão da co-evolução das estruturas institucionais e dos comportamentos dos atores e, de maneira mais geral, a mudança e a evolução da ação pública.

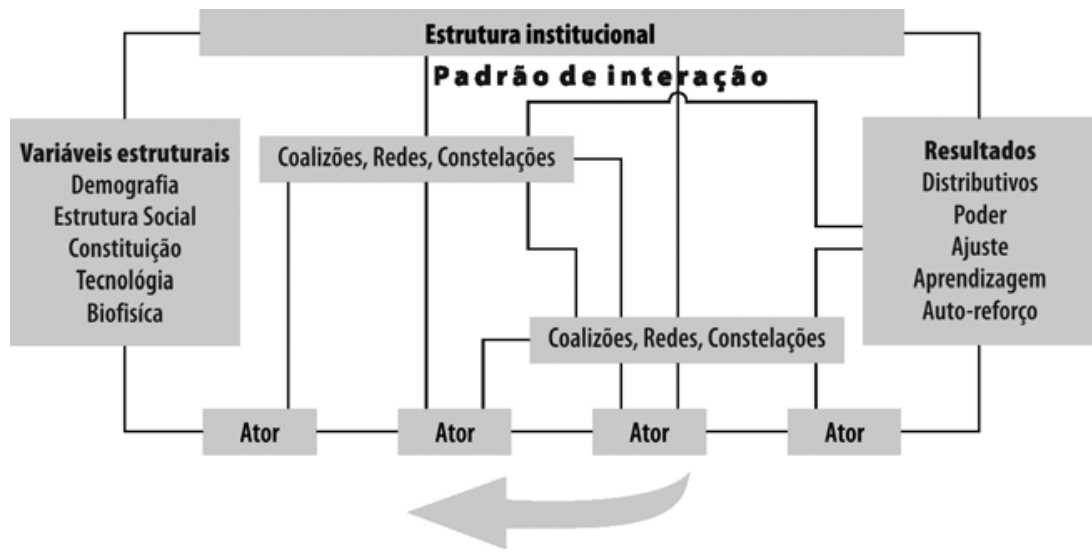

Este quadro de análise institucional da política procura combinar as idéias de vários autores neo-institucionalistas. Destaca o investimento analítico realizado por Ostrom $(1990,2005)$ para identificar o conjunto de elementos (Box 1) comuns a toda situação de interdependência (action situations) que caracterizam as políticas. Na estrutura analítica desenvolvida pela cientista político, os atores, suas posições e seu acesso às 
informações representam variáveis independentes. Assim, diferentes combinações destes elementos resultam em políticas distintas. Como vimos anteriormente, a análise dos processos de formulação de políticas por Ostrom leva também em conta uma reflexão sistemática sobre as regras e os pressupostos comportamentais dos atores.

\section{Box 1: elementos básicos da Análise Institucional de Ostrom}

Os participantes da situação, i.e., o número de atores (muitos/poucos) seus atributos (individuais/coletivos), seus recursos (importantes/insignificantes) e atributos (por exemplo, velho/jovem);

As posições na situação, i.e., as funções desempenhadas pelos participantes e a sua hierarquia (relator de uma comissão, órgão administrativo a cargo da execução da política, grupos de pressões que realizam atividades de lobbying, organização não governamental que monitora intervenções públicas, etc.).

Um conjunto de ações permitidas, i.e., o conjunto de alternativas possíveis dadas às restrições de ordem tecnológica ou institucional.

Os resultados potenciais, i.e., as oportunidades e os efeitos possíveis envolvidas nas ações dos participantes assim como os processos que relacionam ações e suas consequências.

O grau de controle sobre as decisões, i.e., o conjunto de probabilidades que uma ação afeta os resultados potenciais.

As informações sobre a situação, em particular, as informações a respeito dos recursos em jogo, os ganhos potenciais, os demais jogadores, etc.

Por fim, os custos e benefícios, i.e. os custos e benefícios esperados de cada conjunto de ações.

Fonte: Ostrom (2005)

Além disso, o quadro de análise procura retomar as ideias encontradas na abordagem do institucionalismo centrado nos atores desenvolvido por Scharpf (1997) e Mayntz e Scharpf (2001). Para estes autores, a formulação de políticas públicas resulta da interação de redes (ou constelações) de atores num sistema institucional específico. Ao nível dos atores, as instituições orientam e determinam suas capacidades de ações. Mas como é improvável que existe um ator com capacidade de determinar individualmente os resultados de uma política, estes dependem das estratégias das redes de atores e dos padrões de interações que as caracterizam. 
Scharpf (1997) considera que uma constelação descreve os atores envolvidos, suas opções estratégicas e suas preferências sobre os resultados possíveis. A análise das políticas deve, além disso, especificar os padrões de interações. Em particular, precisa explorar a natureza dos processos de negociações e coordenações levados adiante por constelações de atores. Em definitivo, para Scharpf, a combinação das estratégias desenvolvidas por constelações de atores e dos padrões de interações é a principal variável explicativa do processo de formulação da política e de seus resultados.

Os atores, a estrutura institucional e os modos de interação são os componentes básicos das situações de interdependências que caracterizam uma política. Mas para compreender porque estas situações se criam e se desenvolvem é preciso prestar atenção aos resultados distributivos e as relações de poder. É o que sugere Tsebelis $(1998,2002)$ quando indica que instituições redistributivas servem dois propósitos: a preservação dos interesses estabelecidos ou uma nova maioria incorporando perdedores anteriores. Este autor destaca também que a atribuição de poderes de veto a alguns atores é uma característica básica da estrutura institucional. Para Knight (1992) as instituições não surgem para restringir os indivíduos ou os grupos. Mais fundamentalmente, elas expressam os conflitos relativos à distribuição do produto social. Bardhan (2005) assinala que em contextos marcados pela heterogeneidade e a desigualdade social no acesso aos recursos, à mudança institucional corresponde a uma alteração das relações de poder. A posição de Schmid (2005) caminha na mesma direção. Para este autor, o problema básico para analisar os efeitos de uma política é saber quem recebe o quê. Recomenda que se reconheça que a estrutura institucional afeta diversamente os custos dos participantes, os direitos de uns sendo custos para outros. Ou seja, as regras (formal ou informal) são fontes de poder e têm impactos distributivos.

Sistemas de regras diferentes têm efeitos dispares sobre os direitos e as capacidades de ações dos participantes da política. Mudanças institucionais podem assim alterar as relações de dependência, uma importante fonte de poder entre os atores. Por exemplo, regras que delegam a uma agência a regulação de um setor alocam direitos de decisões a uma instituição particular. Num contexto em que as ações da agência têm credibilidade, as crenças e preferências dominantes na agência terão um impacto significativo no processo de formulação da política. Da mesma forma, se as decisões da agência impactam fortemente os interesses dos demais atores envolvidos, a agenda desta será privilegiada no processo decisório. Simetricamente, isso não ocorrerá quando as decisões da agência têm baixa credibilidade ou quando os demais atores envolvidos na política dependem pouco de sua atuação institucional. Nesse caso, a agência terá pouco poder de influenciar a formulação da política. Em suma, na situação de interdependência que caracteriza a formulação da política, o poder de cada ator, depende fundamentalmente de como as regras alteram as capacidades de ações e de como essa distribuição influencia o conteúdo e o grau de dependência mútua dos atores da política. 
Um quadro de análise da formulação de políticas deve também incorporar a questão da aprendizagem, um aspecto pouco tratado pela abordagem neoinstitucionalista embora se trate de um subproduto fundamental dos investimentos realizados pelas constelações de atores envolvidos. Como observa Heclo (1974) parte importante das interações políticas induzidas por um programa constitui um processo de aprendizagem social. Por exemplo, populações afetadas pela construção de uma hidrelétrica, mas que não tinham capacidades de ações apropriadas podem aprender novas formas de mobilização e desenvolver estratégias de contenções políticas. O governo pode também aprender a criar espaço de deliberação que melhoram a qualidade e a legitimidade da política. A implantação da política pode também induzir o nascimento de rotinas organizativas que poupam tempo e beneficiam a coordenação das tarefas, melhorando a eficácia geral da ação pública. As melhorias operacionais nesse caso traduzem a aprendizagem pela implementação - learning by implementing (Bennett \& Howlett, 1992).

Num plano mais amplo, o sucesso, o fracasso ou, melhor dizer, os problemas de uma política podem reforçar ou alterar as estratégias das redes de atores e mudar os condicionantes externos, estabelecendo um feedback entre resultados, comportamentos e parâmetros estruturais. O sucesso de uma política tende a promover não somente processos de replicação e imitação institucional como beneficia certos grupos sociais que provavelmente defenderão sua manutenção. Os exemplos das políticas de modernização da agricultura que reforçaram certos pacotes tecnológicos e os direitos de decisão de alguns dos grupos de atores são exemplos da importância de processos de auto-reforço. Por outro lado, existem diversos exemplos mostrando que dificuldades insuspeitadas podem estimular a criatividade dos atores e levá-los a soluções, elas mesmas não antevistas. Hirschman (1963) observou processos desse tipo na implementação de diversos projetos de desenvolvimento na década de 1960. Segundo as observações do economista, a dinâmica dos programas públicos dependia das soluções encontradas para remediar problemas inicialmente ignorados devido à tendência dos planejadores em basear suas avaliações "ancoradas" num conjunto restrito de informações e à suas dúvidas a respeito do conjunto de soluções possíveis e alcançáveis. Problemas de natureza biofísica como a qualidade da matéria prima, por exemplo, podem levar os atores a encontrarem ou desenvolverem novas soluções. Se os atores forem comprometidos com o programa e os conflitos administráveis, algum tipo de solução será provavelmente encontrada, seja ela tecnológica, política ou econômica.

A seguir, procura-se entender o processo de formulação do Programa Nacional de Produção e Uso de Biodiesel (PNPB) a luz do quadro analítico aqui esboçado. 


\section{O processo de formulação do Programa Nacional de Produção e Uso de Biodiesel}

O Brasil é um país com uma experiência única na promoção de energias renováveis a partir da biomassa. Como é conhecido, nos anos setenta, em resposta à crise internacional do petróleo e a baixa remuneração do açúcar, o Brasil lançou uma política de incentivos para as energias renováveis por meio do incremento da produção de etanol de cana-de-açúcar. O que é menos conhecido é que poucos anos depois se iniciaram experiências na produção de biodiesel com o objetivo de substituir parte do diesel mineral importado ${ }^{8}$.

Contudo, a efetiva incorporação do biodiesel à agenda das políticas energéticas brasileiras só se deu no início dos anos 2000 com o lançamento do Programa Brasileiro de Biocombustíveis (PROBIODIESEL). Ainda que o desenho do programa contasse com a participação efetiva de mais de 200 especialistas e organizações interessadas reunidas na Rede Brasileira de Biodiesel, as discussões relativas à possível substituição do diesel mineral por um biocombustível de óleos vegetais se mantiveram no nível das pesquisas acadêmicas e dos aspectos tecnológicos. As principais motivações para a implantação do PROBIODIESEL eram: 1) a diminuição da dependência dos derivados do petróleo; 2) a criação de novos mercados para oleaginosas, em particular para a soja; 3) o crescimento da demanda global por combustíveis alternativos e 4) a redução das emissões de gás carbônico. Mas com a chegada de Luiz Inácio Lula da Silva à presidência no final de 2002, o programa sofreu uma importante reformulação.

Ao lado das questões da segurança energética e da eficiência econômica, o objetivo do programa passou a conter metas de inclusão social, desde o início um dos pilares da legitimidade do novo governo. Com o objetivo de conduzir a reformulação do programa, em 2003 é instituído um Grupo de Trabalho Interministerial (GTI) para realizar estudos sobre a viabilidade de utilização de óleo vegetal. A gestão da política de biodiesel foi transferida então do Ministério da Ciência e Tecnologia (MCT) para a Casa Civil, o que de certa forma refletia as mudanças de preocupações em torno do novo combustível e o maior peso dado a este tipo de política na agenda política brasileira. Em janeiro de 2005, por meio da lei 11.097 se criava o Programa Nacional de Produção e Uso de Biodiesel (PNPB).

O novo desenho do programa elencava três pilares fundamentais: a inclusão social por meio da agricultura familiar, a sustentabilidade ambiental e a viabilidade econômica. O biodiesel foi definido como um combustível de uso obrigatório que deveria ser adicionado ao diesel do petróleo em porcentagens que variavam de acordo com as metas estabelecidas: originalmente 2\% entre 2008 - 2012 e em 5\% a partir de 2013. Antes de 2008 sua adição ao diesel era facultativa. A Agência Nacional do Petróleo e Gás Natural passou a se chamar Agência Nacional do Petróleo, Gás Natural e Biocombustíveis e a lei estabelecia que, se necessário, o Conselho Nacional de Política Energética (CNPE) poderia antecipar os níveis de mistura ao diesel. O PNPB 
incentivou a consolidação do mercado de biodiesel por meio de leilões públicos promovidos pela ANP disputados em condições diferenciadas pelas empresas que possuem o Selo Combustível Social (SCS). A instituição dos leilões tinha como principal objetivo garantir que as metas produtivas estipuladas pelo PNPB fossem alcançadas sem problemas de desabastecimento. Além dos leilões e da obrigatoriedade, o PNPB definiu um sistema tributário diferenciado para garantir a inclusão social.

Todavia, o cronograma inicial e a estrutura institucional sofreram várias alterações. Os prazos das metas estabelecidas foram encurtados: o $2 \%$ foi autorizado em 2005 , o 3\% em 2009 e o 5\% em 2010. Solicitado pelos produtores de biodiesel e avaliado positivamente pelo governo, este ajuste no cronograma proporcionou uma demanda crescente e segura para a indústria. Não por acaso, o PNPB conseguiu induzir a formação de um parque industrial capaz de atender a uma demanda de cerca de dois bilhões e meio de litros de biodiesel no curto espaço de seis anos. Além disso, foram alteradas as regras de participação nos leilões de biodiesel organizados pela Agência Nacional do Petróleo, Gás Natural e Biocombustíveis (ANP). No começo do programa, os leilões eram eletrônicos. O objetivo era promover a impessoalidade necessária ao bom funcionamento dos mecanismos de mercado. Num contexto ainda marcado pela incerteza quanto ao desenvolvimento do mercado do biodiesel, as regras estabelecidas, no entanto, incentivaram práticas de preços predatórias por parte das empresas, resultando em deságio importante nos primeiros leilões. Nos leilões seis e sete, por exemplo, o deságio médio foi de mais de $22 \%$. Como o grupo menos robusto da indústria não se sentia capaz de sustentar esse padrão de mercado, havia temor de quebra. No estágio embrionário no qual se encontrava a indústria brasileira de biodiesel naquele momento, a possibilidade de falências era bastante crível e as perdas não eram somente privadas como políticas. Sem informações adequadas sobre o estado de saúde das empresas e temendo o fracasso de um programa econômica e politicamente atraente, o governo concordou em alterar as regras e a ANP instituiu pregões presenciais. O resultado desse ajuste institucional foi imediato: o deságio médio nos dez leilões seguintes não ultrapassou os $8,40 \%$. A ANP, além de alterar as regras no intuito de garantir maior estabilidade dos preços, elevou os preços de referência - já a partir do sexto leilão - de modo que as condições de lucratividade da indústria melhoraram bastante. Ainda que os leilões presenciais tenham terminado - a partir do décimo sétimo leilões voltaram a ser eletrônicos -, o ajuste promovido no momento de maior incerteza quanto ao futuro da oferta de biodiesel revelou-se estratégico para o sucesso produtivo do programa.

Contudo, do ponto de vista distributivo e da justiça social, os resultados do PNPB são mais desanimadores, estando longe de atingir as metas esperadas inicialmente. O principal diferencial do PNPB em relação a outras políticas energéticas foi procurar estimular a produção de um novo combustível e promover a inclusão da agricultura familiar, nordestina em particular. Este aspecto, além de representar um fator de legitimidade para o governo e alimentar as expectativas das bases sociais que o 
apoiaram, era visto como fundamental para promover um modelo de desenvolvimento socialmente mais justo. No entanto, este tem sido um dos aspectos mais problemáticos do programa. A capacidade de inclusão do PNPB tem sido muito aquém do que se esperava inicialmente ${ }^{9}$. A manutenção do programa no nordeste, em particular, só ocorre por causa da atuação da Petrobras Biocombustíveis que funciona com três usinas $^{10}$. Além disso, a cadeia de soja mostrou-se a única estrutura organizacional capaz de responder aos desafios postos pela necessidade de abastecer um mercado desse tipo e dessa amplitude. Com efeito, a soja mostrou-se a única matéria-prima com oferta estruturada, segura e abundante de modo que cerca de $80 \%$ do biodiesel brasileiro foi produzido a partir da soja (as demais matérias-primas significativas são o sebo bovino e o girassol). O PNPB, nesse sentido, transferiu um volume de recursos não desprezível para os sojicultores do Centro-Oeste e Sul do Brasil, resultando num efeito distributivo não esperado e perturbador para as aspirações sociais do programa.

\section{Redes de atores e modos de interação do PNPB}

No âmbito do PNPB, é possível distinguir três redes de atores influentes. A primeira pode ser denominada de redes de atores da área energética. Nesta interagem atores relacionados com a problemática energética seja porque têm atribuições de jure como é o caso do Ministério de Minas e Energia (MME) ou da ANP seja porque ocupam uma posição econômica privilegiada no setor de energia como é o caso da Petrobras. É neste grupo que se concentram os conhecimentos expert, as rotinas e as informações estratégicas para o planejamento energético.

O papel do Ministério de Minas e Energia (MME) no PNPB é principalmente o de colocar o novo combustível no mercado e manter a oferta do produto com qualidade, além de sustentar o abastecimento de longo prazo, assegurando o abastecimento e a 
compatibilidade tecnológica. Essa atribuição dá à instituição e aos seus funcionários uma posição privilegiada quando se discute as normas que definem os atributos técnicos do produto ou as decisões acerca do seu alcance futuro. Além disso, o MME preside o Conselho Nacional de Política Energética (CNPE) que pela lei 11.097/05 tem o poder de definir os prazos de adição de biodiesel e, portanto, o ritmo de crescimento do mercado ${ }^{11}$. O MME divide parte da ação de normatização do PNPB com a ANP. Em particular, cabe a ANP toda a especificação do novo combustível, bem como a regulamentação e realização dos leilões que são o dispositivo institucionalizado para a distribuição e comercialização do biodiesel. Dado seu foco tradicional na regulação dos hidrocarbonetos, a agência tem mostrado maior preocupação com a qualidade necessária ao bom desempenho do produto, definida através de um conjunto de características físico-químicas e seus respectivos limites.

A Petrobras e, mais recentemente, a Petrobras Biocombustíveis são outros atores que desempenham um papel ativo no PNPB. Após participar do desenho inicial do programa e ocupar uma posição dominante na comercialização do biodiesel, a empresa se estabeleceu também como um produtor de peso no mercado. Para tanto, construiu três usinas e dispõe de robustas capacidades operacionais e logísticas e amplos recursos financeiros. A Petrobras, que em 2009 iniciou a produção de biodiesel em três plantas se tornou de fato um ator incontornável da evolução do mercado de biodiesel, mas ao participar mais diretamente da produção de matéria-prima tem que disputar também espaço na rede que concentra os atores do agronegócio.

Cabe por fim sinalizar a presença nessa rede da Associação Nacional dos Fabricantes de Veículos Automotores (ANFAVEA). A organização que integrou o grupo de trabalho interministerial responsável pelo estudo e pela elaboração da proposta do PNPB tem sido um interlocutor ativo na hora de definir os padrões de qualidade do biodiesel. Ainda que seja favorável a introdução de novas alternativas energéticas capazes de reduzir o preço dos combustíveis e gerar impactos ambientais positivos, a ANFAVEA tem sido atuante na elaboração de normas e demandas por testes exaustivos. Seu objetivo é condicionar a introdução do novo combustível, pelo menos no curto e médio prazo, a não realização (ou à realização marginal) de modificações na sua rota tecnológica. A capacidade de elaborar uma agenda técnica - como é o caso do documento-referência denominado de Proposta de Ensaios em Laboratório com Misturas de Biodiesel - favorece as relações da ANFAVEA com a ANP e a dota de um peso significativo nas propostas de alteração do PNPB discutida no âmbito do Conselho Nacional de Política Energética.

O segundo influente grupo é aquele composto por uma constelação de atores públicos e privados representativos dos interesses agrícolas dos produtores de matéria-prima para o biodiesel. Pode, por este motivo, ser qualificada de rede de atores do agronegócio. Nesta rede de atores distinguem-se instituições públicas como o Ministério da Agricultura, da Pecuária e do Abastecimento (MAPA) e a EMBRAPA grupos de interesses especiais como a União Brasileira do Biodiesel (UBRABIO), a 
Confederação Nacional da Agricultura (CNA), a Associação Brasileira das Indústrias de Óleos Vegetais (ABIOVE) ou a União da Indústria de Cana-de-Açúcar (UNICA) e grupos representantes interesses regionais como é o caso do Sindicato das Indústrias de Biodiesel no Estado de Mato Grosso (SindiBio). Dada a proximidade dessas diversas instituições no que diz respeito às questões ideológicas e à existência de interesses em comuns, os padrões de interação nessa rede são geralmente mais cooperativos do que conflitivos.

Dentro do governo, o principal ator é o MAPA que participou desde o início da formulação do PNPB. Além de ser responsável pela realização de pesquisas para o desenvolvimento de oleaginosas, com foco na obtenção de uma maior eficiência por hectare plantado, o ministério tem sido ativo no apoio as reivindicações dos grupos de interesses dos produtores e da indústria produtora de óleos vegetais como a ABIOVE ou a CNA. A representação dos interesses específicos da indústria de biodiesel, contudo, é assegurada pela União Brasileira do Biodiesel (UBRABIO) e pela Associação dos Produtores de Biodiesel do Brasil (Aprobio) que surgiu em 2011 devido ao descontentamento de várias usinas com a atuação da UBRABIO. As representações dos interesses dos produtores não participaram do grupo de trabalho interministerial que elaborou o estudo e a proposta do PNPB. Mas desde então têm participado ativamente dos fóruns de discussão públicas através de seminários, workshops, grupos de trabalho e comissões.

A terceira rede pode ser classificada como rede de atores do desenvolvimento agrário. Devido à ambição do PNPB no que tange a inclusão dos agricultores familiares na cadeia produtiva de biodiesel este espaço de interação é caracterizado pela presença de sindicatos, de movimentos sociais, de organizações não-governamentais e de alguns setores do governo como o Ministério de Desenvolvimento Agrário (MDA). Este último participou desde o início da formulação do PNPB com o objetivo de que a agricultura familiar viesse a ser participante ativa de um eventual programa de biodiesel. Desde a institucionalização do programa, o MDA procurou motivar as organizações representativas dos interesses dos agricultores familiares. Todavia, diante de um contexto em que mais de $80 \%$ da produção de biodiesel é proveniente da soja, a atuação do Ministério do Desenvolvimento Agrário (MDA) tem sido alvo de críticas oriundas tanto por parte do governo quanto de organizações do agronegócio e dos movimentos sociais ${ }^{12}$.

Ao lado do MDA, a Contag é um dos atores mais atuantes desse grupo. Por ter sido escolhido como interlocutor privilegiado na implementação do PNPB a Contag decidiu apoiar a implantação do programa com diversas ações e, inicialmente, priorizou a sua atuação no que tange à política de biodiesel na região Nordeste. Isto se refletiu em parcerias com a Brasil Ecodiesel na região. No entanto, com o passar do tempo e diante dos problemas enfrentados para incorporar os segmentos fragilizados da agricultura familiar, a Contag passou a emitir críticas, ainda que oficialmente mantenha seu apoio ao programa. Entre outros pontos falhos do PNPB, as lideranças da Contag destacam: 
a insuficiência de mecanismos para alavancar a produção de oleaginosas oriunda da agricultura familiar; política de crédito; assistência técnica; zoneamento das oleaginosas; seguros e política de preços. Este último ponto é considerado um gargalo e tem gerado conflitos entre os movimentos sociais, empresas e governo. Com efeito, com a alta dos preços da soja ou da mamona observado em 2007 e 2008, os contratos de comercialização firmados com as empresas produtoras de biodiesel se tornaram custosos, criando uma situação de conflitos de interesses marcada por incentivos à quebra contratual.

De maneira geral, é ambígua a posição dos movimentos sociais em relação ao PNPB. Por exemplo, os movimentos sociais ligados à Via Campesina como o Movimento dos Trabalhadores Rurais Sem Terra (MST), Movimento dos Atingidos por Barragens (MAB), o Movimento dos Pequenos Agricultores (MPA) e a Comissão Pastoral da Terra (CPT) não apresentam uma visão fechada sobre o assunto. Enxergam a produção de agrocombustíveis com desconfiança, no caso do Biodiesel brasileiro têm adotado uma posição que varia de acordo com os movimentos em questão, com os estados onde atuam e com a cultura a ser implantada. Por exemplo, segundo o relatório elaborado em 2008 pela Rede Brasileira pela Integração dos Povos (REBRIP) e pela Federação de Órgãos de Assistência Social e Educacional (FASE), os movimentos sociais entendem que o PNPB não está sendo capaz de fortalecer a agricultura familiar e camponesa. Entretanto, não há consenso sobre o posicionamento quanto ao desenho e estratégia de implantação da política (REBRIP ; FASE, 2008:134).

De maneira geral, espera-se que um elevado número de atores com interesses, recursos e valores muito diferentes gere um aumento da complexidade da formulação da política e uma maior assimetria de poder entre as redes atores. Mas, nem todos os atores têm peso equivalente na hora de definir a agenda ou influenciar a tomada de decisões. Os direitos de decisão se concentram em maior número na rede de atores da área energética. Os interesses dominantes (MME, ANP ou Petrobras) podem ser mais diluídos do que a maioria dos atores que interagem nas demais redes de atores, já que grande parte de seus recursos são alocados para outros fins e operações (petróleo, gás, eletricidade etc.). Mas, como se trata do espaço privilegiado para discutir e estabelecer os critérios técnicos que definem as características do produto vendido e regulam o formato dos mercados, as preferências e valores dos principais atores da área energética se convertem em parâmetros decisivos na arena da política.

Encontram-se também atores com poder de veto nas demais redes de atores, como mostram as bem sucedidas demandas da UBRABIO por revisões do cronograma de aumento dos índices de misturas obrigatórias ou o maior envolvimento da Petrobras na montagem de um sistema de produção no Nordeste. No contexto que marcou o início da implementação do PNPB, a rede de atores do agronegócio detinha importante direitos de decisões já que não havia informações a respeito da oferta do biocombustível. Essa situação deixava os demais participantes do programa, principalmente aqueles de maior influência na área energética, dependentes das 
decisões tomada pelos produtores de biodiesel e pelos seus representantes e contatos políticos. No entanto, com a implantação do PNPB e a difusão dos resultados alcançados, o contexto mudou. Após seis anos do programa, todos os atores envolvidos sabem (que todos sabem) que não há restrição material do lado da oferta. Esse conhecimento comum altera os parâmetros do jogo político e tem um impacto sobre a alocação dos direitos de decisões. Um dos efeitos é a diminuição dos padrões de interação cooperativos entre atores da rede de energia e da rede do agronegócio.

A situação e a dinâmica política do PNPB estão também redefinindo as conseqüências possíveis de uma modificação dos parâmetros externos. Uma mudança tecnológica ou na percepção da legitimidade social do programa podem impactar os padrões de interação e os resultados do PNPB. Por exemplo, um impacto negativo dos efeitos distributivos do PNPB sobre a legitimidade social do programa pode favorecer uma aproximação entre as redes de atores da área energética e agrária. Diferentemente, uma onda de inovações que atingem a produção de matéria prima (algas) ou os processos de produção (biodiesel de cana) pode estimular certo fechamento da área de energia sobre si mesma ou, ao contrario, estimular sua conexão com novos grupos

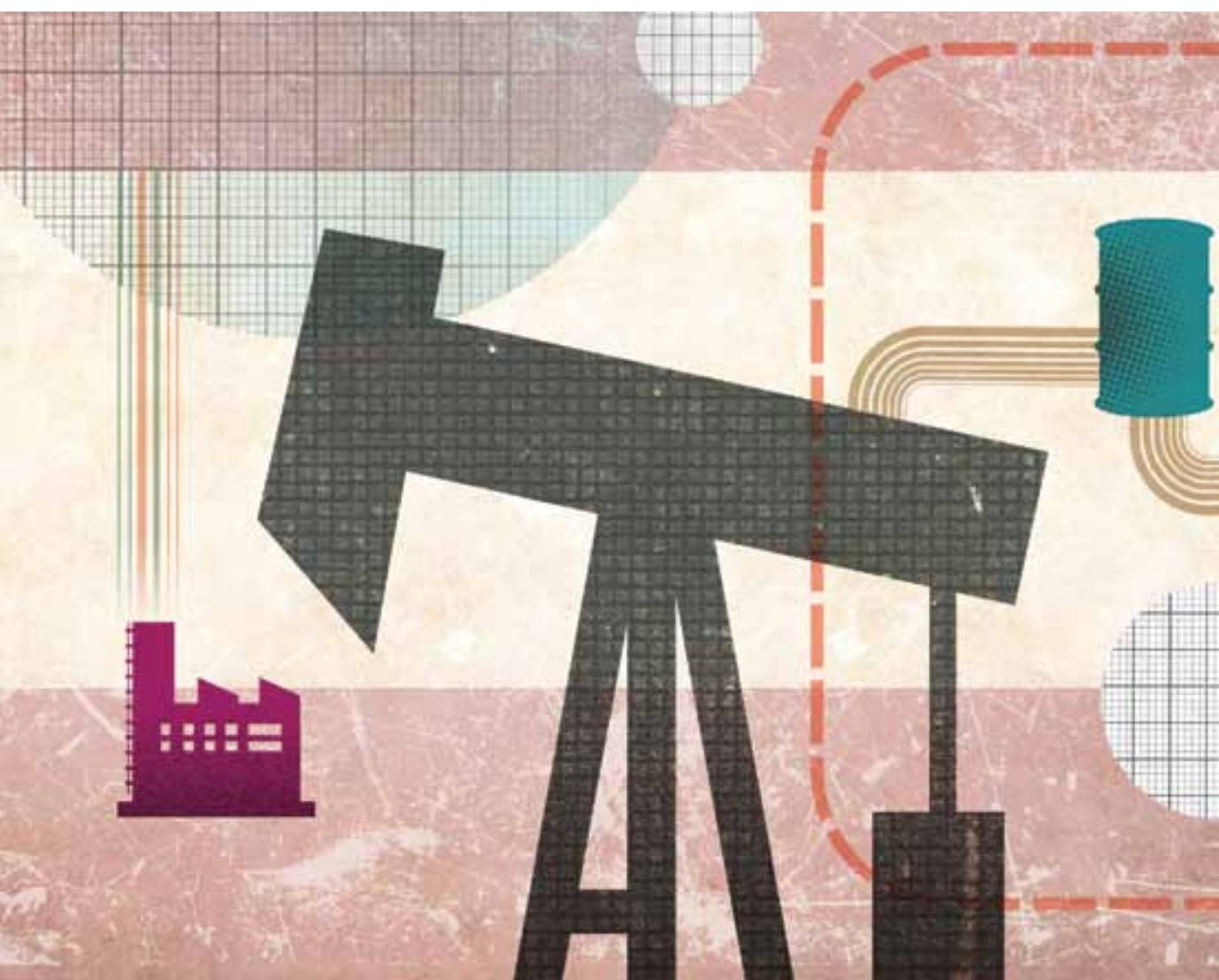


de atores do agronegócio. Em definitivo, dadas suas diferentes dimensões - sociais, energéticas e econômicas - e a atuação de um grande número de atores, o equilíbrio político do PNPB parece estruturalmente instável.

\section{Conclusão}

O processo de formulação de políticas é um objeto complexo. O objetivo do quadro de análise apresentado no presente trabalho consiste em mostrar que é possível lidar com essa complexidade se for considerado o comportamento e a aprendizagem dos atores, os modos de interação resultando das estratégias das redes de atores, os incentivos e restrições institucionais e a dinâmica distributiva da política. Dessa forma, distancia-se de análises de políticas que se baseiam em critérios positivos como a eficiência dos mercados competitivos ou em pressupostos estruturais como os estágios de desenvolvimento das forças sociais. Para tanto, o quadro de análise combina idéias e argumentos das abordagens neoinstitucionalistas da política, em particular aqueles desenvolvidos pela teoria da racionalidade limitada e do institucionalismo centrado nos atores. Adere, nesse sentido, a uma corrente intelectual que tem procurado analisar e explicar problemática como a diversidade dos modos de governança das políticas ou os determinantes políticos do crescimento econômico e da reforma institucional.

O quadro de análise procura também destacar a importância das questões das relações de poder e dos efeitos distributivos nas políticas, questões que têm recebido menos atenção nas abordagens neoinstitucionalistas do que aquelas relacionadas com a diversidade das formas de governança e dos problemas de coordenação. Nesse sentido, reconhece que as políticas implicam uma distribuição de recursos e que nesse processo nem todos os atores têm capacidades de ação e direitos iguais. A incorporação dessas questões à análise da formulação de políticas permite provavelmente uma melhor compreensão dos obstáculos à mudança institucional, dos custos de transição políticos ou da permanência de situações coletivamente indesejáveis.

O Programa Nacional de Produção e Uso de Biodiesel proporcionou uma possibilidade para aplicar as idéias da abordagem neoinstitucionalista da política. A montagem e o desenho do PNPB envolveram muitos atores nos processos de decisão. Essa característica facilitou a troca de informação e a legitimidade da política, mas o elevado número de atores - com interesses, recursos e valores muito diferentes - a tornou mais instável e, também, sujeita a diversos conflitos. Como mostrou o PNPB, a heterogeneidade das preferências, dos valores e dos recursos das diferentes redes de atores envolvida na política pode levar a padrões de interações instáveis que impactam sua dinâmica.

Para finalizar cabe tecer algumas considerações a respeito da dimensão normativa subentendida no trabalho. Uma dimensão normativa que merece ser ressaltada diz respeito á legitimidade das escolhas coletivas em situações de incertezas e 
conseqüências não esperadas. Os resultados de um programa podem não estar de acordo com suas aspirações iniciais e as expectativas dos atores envolvidos. No entanto, seus efeitos distributivos de uma política podem dificilmente se sustentar se houver escolhas públicas alternativas, promissoras e realizáveis. Além disso, o foco nas motivações dos atores, nas estratégias das redes e nas conseqüências inesperadas aponta para a importância dos processos de aprendizagem tantos coletivos quanto individuais. Nesse sentido, o quadro de análise assinala a importância de induzir processos de aprendizagens capazes de dotar os atores de maiores competências organizacionais, tecnológicas e comunicativas. Esses aspectos normativos representam provavelmente alguns dos fatores que condicionam o futuro de uma política e sua capacidade de "mudar o mundo".

\section{Notas}

Hirschman (1984: 184), ao tratar da análise da política na América Latina no início da década de 1970, declarou "sentimos agora uma nova inclinação em explorar, quase a partir do zero, os mecanismos das interações entre a economia, a sociedade e o Estado. Pelo menos, é dessa maneira que interpreto o interesse atual pelos estudos detalhados dos determinantes e das conseqüências das políticas públicas"

2 O modelo racional, o modelo do comportamento organizacional da admi-nistração e o modelo da concorrência político-administrativa.

3 Para Sabatier (2007), por exemplo, a complexidade dos processos de for-mulação de políticas devese a um conjunto de razões: 1) o grande número de atores; 2) a temporalidade dos processos; 3) as externalidades da política; 4) a crescente tecnicidade e fragmentação dos conhecimentos levantados pela política; 5) a natureza dos conflitos distributivos produzidos pela política

4 Vale lembrar que se trata de uma hipótese metodológica e não de uma posição ontológica.

5 Mais precisamente racionalidade limitada é a idéia de que na tomada de decisões, a racionalidade dos indivíduos é limitada pela informação que dispõem, as limitações cognitivas de suas mentes, e as limitações de tempo que eles têm que tomar uma decisão.

6 Dissonância cognitiva é um termo da psicologia social, que se refere ao conflito entre duas ou mais idéias, crenças ou opiniões incompatíveis. O desconforto provocado por esse conflito cognitivo induz uma mudança de uma ou mais crenças, ou as duas, para torná-las mais compatíveis.

7 O desconto hiperbólico é uma inconsistência intertemporal que estipula que para ganhos esperados iguais, um indivíduo apresenta uma preferência para aquele que se materializa o mais rápido. Traduz a preferência pelo presente.

8 Uma das primeiras experiências institucionais mais importantes com o biodiesel no Brasil foi realizada em 1980 com a criação do o Programa Nacional de Óleos Vegetais para Fins Energéticos - Pro-óleo, cujo objetivo era promover a substituição de até 30\% do óleo diesel mineral. Após um curto período de existência é abandonado em 1986. Nesta mesma época a Secretaria de Tecnologia Industrial do Ministério da Indústria e Comércio (STI/MIC) desenvolveu e lançou o Programa Nacional de Alternativas Energéticas Renováveis de Origem Vegetal (OVEG), que tinha objetivo de comprovar a viabilidade técnica do uso dos óleos vegetais em motores ciclo diesel.

9 Apenas um quarto dos 400.000 agricultores familiares esperados inicialmente estão incorporados ao programa em 2011.

10 As três usinas estão localizadas em Quixadá no Ceara, em Candeias na Bahia e em Montes Claros no norte de Minas Gerais.

11 O CNPE é composto pelo Ministro de Minas e Energia, que o preside; pelo ministro de Ciência e Tecnologia; pelo Ministro do Planejamento, Orçamento e Gestão; pelo Ministro da Fazenda; pelo Ministro do Meio Ambiente; pelo Ministro do desenvolvimento, Indústria e Comércio Exterior; 
pelo Ministro da Casa Civil; por um representante dos Estados e do Distrito Federal; por um especialista em energia; e por um representante de universidades brasileiras.

12 Essas críticas levaram o MDA a atuar de maneira mais agressiva, suspendendo o Selo Combustível Social de algumas plantas industriais que não cumpriam as condições contratuais pactuadas no Selo. O cancelamento do Selo Com-bustível Social implica a perda dos contratos, a não participação em leilões que exigem o Selo, além da perda dos direitos aos benefícios fiscais da redução de PIS/Pasep e Cofins e das vantagens nas linhas de financiamento do Banco Nacional de Desenvolvimento Econômico e Social (BNDES)

\section{Referênciass Bibliográficas}

ALLISON G. (1971) Essence of decision: explaining the Cuban Missile Crisis, Little Brown

AKERLOF, G. \& SHILLER, R. (2009) Animal Spirit, Princeton University Press

BARDHAN, P. (2005) Scarcity, Conflicts and Cooperation: Essays in the Political and Institutional Economics of Development, MIT Press

BENNETT, C. J. \& HOWLETT, M. (1992), "The lessons of learning: reconciling theories of policy learning and policy change". Policy Sciences, 25 (3): 275-294.

CRAWFORD, S. \&, OSTROM, E., (1995) "A grammar of institutions", The American Political Science Review 89, 582-600.

ELSTER, J. (2009) Ulisses liberto: estudos sobre racionalidade, pré-compromisso e restrições. São Paulo: Editora Unesp.

(2010) L'irrationalité: Traité critique de I' homme économique, Seuil

FESTINGER, L. (1957) A Theory of Cognitive Dissonance. Stanford University Press

HECLO, H. (1974) Modern Social Politics in Britain and Sweden: From Relief to Income Maintenance. New Haven, Conn: Yale University Press.

HIRSCHMAN, A.O. (1963) Journey toward Progress, The Twentieth Century Fund (1984) De la economia a la política y mas allá, Fondo de Cultura Económica

KAHNEMAN, D., \& TVERSKY, A. (1984) "Choices, values, and frames". American Psychologist 39:341-50

KNIGHT J. (1992) Institutions and Social Conflict. Cambridge Univ. Press

MAYNTZ, R. \& SCHARPF, F. (2001) “L' institutionnalisme centre sur les acteurs”, Politix, 14(55); 95-123

NELSON, B. (1996) "Public Policy and administration: an overview”, GOODIN R.E.\& KLINGEMANN, H. D. (org.) A New Handbook of Political Science, Oxford University Press, 551-590

OSTROM, E. (2005) Understanding Institutional Diversity, Princeton University Press (1990), Governing the Commons: The Evolution of Institutions for Collective Action, New York: Cambridge University Press.

(1998), "A Behavioral Approach to the Rational Choice Theory of Collective Action," 92(1) American Political Science Review, 1-22

(2003) "Toward a Behavioral Theory Linking Trust, Reciprocity and Reputation."

In, Trust and Reciprocity: Interdisciplinary Lessons From Experimental Research, edited by James Walker. New York: Russell Sage Foundation.

(2000) "Collective action and the evolution of social norms". J. Econ. Perspect. 14,

$137-158$ 
REDE BRASILEIRA PELA INTEGRAÇÃO DOS POVOS (REBRIP). FEDERAÇÃO DE ÓRGÃOS DE ASSISTÊNCIA SOCIAL E EDUCACIONAL (FASE). 2008 Agrocombustíveis e a agricultura familiar e camponesa: subsídios ao debate. Rio de Janeiro: REBRIP/FASE

SABATIER, P. (2007) Theories of the policy process. WestView Press

SCHARPF, F. (1997) Games Real Actors Play. Westview Press

SCHMID, A.A. (2005), Conflict and Cooperation: Institutional and Behavioral Economics, Blackwell, Malden, MA.

SIMON, H. A. (1955) "A behavioral model of rational choice", Quarterly Journal of Economics 69: 99-118.

THALER R. \& SUSTEIN C. (2008) Nudge, Yale University Press

TSEBELIS, G. (1998) Jogos Ocultos, Editora da USP (2002) Veto Players, Russell Sage Foundation

TVERSKY A. \& SHAFIR E. (2004) Preference, Belief and Similarity: Select writings Amos Tversky, MIT Press 